\title{
Early Percutaneous Coronary Intervention for Unprotected Left Main Disease in Patient with Cardiogenic Shock: A Case-Report
}

\author{
Krupal Reddy \\ SevenHills Hospital, Mumbai-400059, Maharashtra, India \\ Email: drkrupal@gmail.com
}

Received 19 April 2016; accepted 10 June 2016; published 13 June 2016

Copyright (C) 2016 by author and Scientific Research Publishing Inc.

This work is licensed under the Creative Commons Attribution International License (CC BY).

http://creativecommons.org/licenses/by/4.0/

(c) () 0 pen Access

\begin{abstract}
The prognosis of left main coronary artery disease is largely affected by the appropriate selection of the treatment strategy. A 45-year-old male presented with severe chest pain and two episodes of ventricular tachycardia, which was reverted after DC shock. Coronary angiography revealed critical stenotic lesion in the left main coronary artery. The patient successfully underwent urgent angioplasty with stent deployment in the left main coronary artery.
\end{abstract}

\section{Keywords}

\section{Left Main Disease, Revascularization, Percutaneous Coronary Intervention}

\section{Introduction}

Left main coronary artery (LMCA) disease is of significant importance, as left main stem (LMS) is responsible for $84 \%$ of the blood supplied to the left ventricle in case of left coronary dominant system [1]. The efficacy and survival benefit of coronary artery bypass grafting (CABG) have established it as the gold standard of care for left main disease [2]-[4]. But the drawback lies in the fact that it is often delayed and as an emergency procedure it can be time-consuming and carries the risk of extensive and irreversible myocardial damage, if not done expeditiously. On the other hand, with recent advances in stent technology and procedure, percutaneous coronary intervention (PCI) warrants prompt reperfusion and restoration of flow without sternotomy, saving the life of patients while maintaining myocardial viability. We report a case of 45-year-old male, with hemodynamic instability and subocclusive LMCA lesion, who underwent an early PCI with a drug-eluting stent resulting in rapid reperfusion of myocardium.

How to cite this paper: Reddy, K. (2016) Early Percutaneous Coronary Intervention for Unprotected Left Main Disease in Patient with Cardiogenic Shock: A Case-Report. World Journal of Cardiovascular Diseases, 6, 175-178. 


\section{Case Report}

We present a case of 45-year-old male, who was a heavy smoker with h/o hypertension, chronic stable angina and hypercholesterolemia. He was admitted from the Emergency Department with complaints of low effort angina, non-radiating and associated with shortness of breath since two days, which got worsened since 2 hours. His initial blood pressure was 98/66. His ECG showed sinus tachycardia with generalized ST segment depression except in AVR. He had two episodes of ventricular tachycardia, which was reverted with DC shock. After stabilization, his BP was 110/70. Patient was taken to catheterization laboratory for rapid reperfusion with PCI. Angiography revealed severe subocclusive lesion in the LMCA beginning from the ostium of left main (Figure 1A, Figure 1B, Figure 1C). Left anterior descending artery (LAD), left circumflex artery (LCX) and right coronary artery (RCA) were normal.

\section{Procedure}

A 6 Fr sheath was placed in the right femoral vein and a 7 Fr arterial sheath was placed in right femoral artery. A Judkins JL 3.5 guide catheter with sideholes was used to cannulate the left coronary artery (LCA) (Figure 1B). A sidehole catheter is used to maintain the flow in coronary artery in patients with LMCA disease and prevents damping of pressure. Heparinization was done to maintain an activated clotting time (ACT) of around 300s. The steerable guide wire of 0.014 inch was then passed across the target stenosis visualized by fluoroscopy view and positioned in the LCX. Another guide wire was placed in LAD artery. A sprinter balloon $(1.5 \times 10 \mathrm{~mm}) \mathrm{was}$ passed over the lesion and inflated at $10 \mathrm{~atm}$ pressure for $10 \mathrm{sec}$. Subsequently, balloon dilatation was performed using a larger balloon (Figure 2). Patient's hemodynamics were continuously monitored. Intra-aortic balloon pump (IABP) was kept standby. As there was calcium in proximal LAD and also there was significant mismatch between size of LMCA and LAD, a decision of putting stent from left main to LCX was done using single stent strategy. A xience prime stent $(3 \times 12 \mathrm{~mm})$ was used, located over the lesion and deployed successfully at 16 atm pressure for $15 \mathrm{sec}$. Post dilatation was done using sprinter balloon. Final angiography showed TIMI 3 flow with $0 \%$ of residual stenosis (Figure 3A \& Figure 3B). There was also an improvement in blood pressure level, while the patient was in the catheterization laboratory. There was also a decrease in ST depression, on the EKG

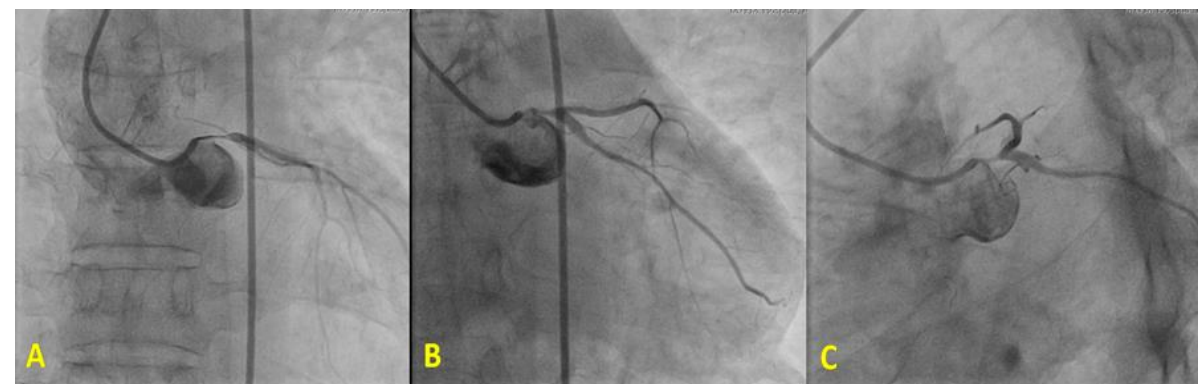

Figure 1. Angiography revealed severe subocclusive lesion in the ostium of LMCA.

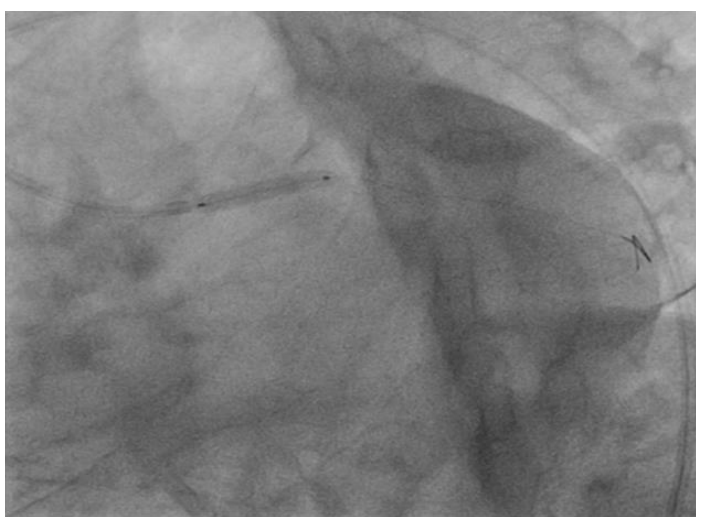

Figure 2. Balloon dilatation using a larger balloon. 


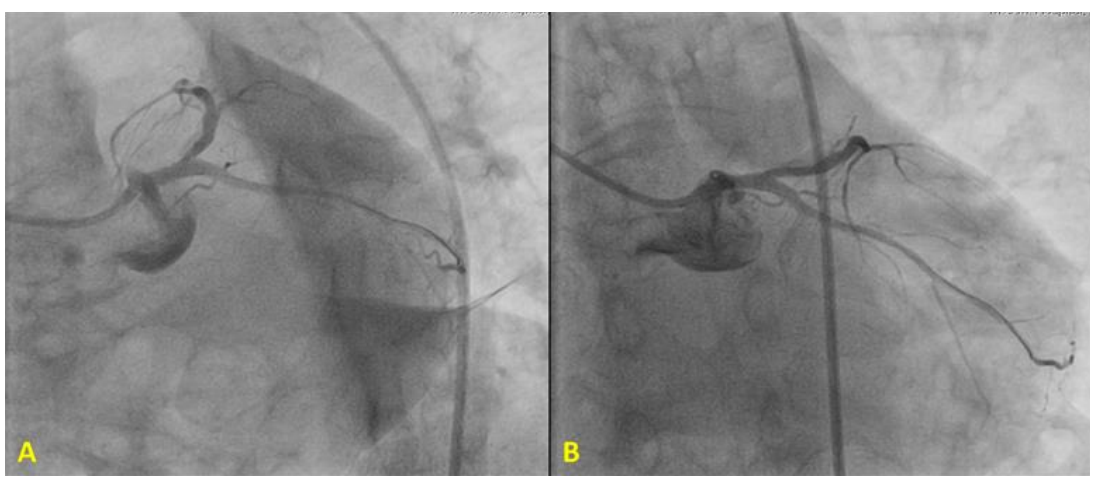

Figure 3. Final angiography.

taken immediately after the procedure. The patient received aspirin $150 \mathrm{mg}$ per day, ticagrelor $90 \mathrm{mg}$ twice daily, and rosuvastatin $40 \mathrm{mg}$ per day. The patient showed gradual improvement in both clinical and hemodynamic parameters and was discharged after 4 days. At three months follow-up, the patient was free of symptoms and did not require any hospitalization. Also, echocardiogram revealed preserved left ventricular (LV) systolic function with an ejection fraction of $50 \%$.

\section{Discussion}

Acute occlusion of left main coronary artery is often accompanied by hemodynamic deterioration and cardiogenic shock. This catastrophic circumstance is colloquially called as the left main shock (LMS) syndrome [5]. LMS is dreaded by every cardiologist, as it has a high mortality rate of approximately 69\% - 94\% [6]. The situation dictates a quick bailout with rapid reperfusion of cardiac muscle. Even, the American College of Cardiology/American Heart Association guidelines for the management of acute myocardial infarction in the presence of cardiogenic shock emphasize immediate $\mathrm{CABG}$ as the first line of treatment [7].

$\mathrm{CABG}$ is a fairly safe alternative. However, as an emergency procedure, it is logistically not always feasible, because even when the operating theatre and the surgical team is available, the preparations for cardiac surgery may take longer than the patient's hemodynamic condition allows. On the other hand, catheter interventions do not require extensive preparations and can be carried out within minutes, leading to immediate restoration of hemodynamics and potentially saving lives. Initially, there was a continuous debate concerning the effectiveness of PCI as compared to CABG in patient with left main stenosis.

But, ever since the advent of new stent technology and technique in percutaneous coronary intervention, there has been growing consensus with regards to PCI being a potentially equivalent option. LeMans trial, first prospective randomized trial on PCI versus CABG in patients with LMS stenosis, demonstrated that there was no significant difference between two groups in the secondary survival outcomes and MACCE rats at 1-year follow-up [8]. Unlike LeMans, PRECOMBAT is a long term trial which enrolls a larger patient population to study the effectiveness of PCI as compared to CABG in LMCA stenosis. The recently evidenced 5-year outcomes of PRECOMBAT trial state that there is no significant difference in MACE rate between PCI and CABG group [9].

Data from SYNTAX trial, which is one of the landmark trials, also demonstrated that at the end of 1-year, there was no significant difference between the groups in the primary endpoint of major adverse cardiac and cerebrovascular events (MACCE). There was a higher incidence of target vessel revascularization in the PCI group but correspondingly, there was also a higher incidence of stroke in the CABG group [10].

Moreover, the American and European guidelines on myocardial revascularization clearly states that a heart team approach should be adopted in patients with LMCA stenosis [11] [12]. The choice of PCI over CABG should take into consideration several anatomic and clinical features and surgical risk of the patient, where ostial LMCA lesion and comorbidities like cardiogenic shock, found in our patient, favours PCI.

The classical electrocardiographic pattern observed in our patient of elevated ST elevation in the lead aVR in the presence of extensive ST depression is a fundamental clue that the patient requires urgent and expedited reperfusion and such patients have the most favourable prognosis when intervened by immediate PCI 0.

Thus, by performing emergency PCI in our patient, we were able to reperfuse the LMCA enabling restoration 
of the coronary blood flow and improving the patient's hemodynamic condition ultimately saving his life and improving his quality of life by preserving his ventricular function as observed at 3-month follow-up.

\section{Conclusion*}

Percutaneous coronary intervention in an unprotected LMCA allows initial revascularization and rapid stabilization of the patient, who experiences acute myocardial infarction and concomitant cardiogenic shock.

\section{References}

[1] Leaman, D.M., Brower, R.W., Meester, G.T., Serruys, P. and van den Brand, M. (1981) Coronary Artery Atherosclerosis: Severity of the Disease, Severity of Angina Pectoris and Compromised Left Ventricular Function. Circulation, 63, 285-299. http://dx.doi.org/10.1161/01.CIR.63.2.285

[2] Eagle, K.A., Guyton, R.A., Davidoff, R., Edwards, F.H., Ewy, G.A., Gardner, T.J., et al. (2004) ACC/AHA 2004 Guideline Update for Coronary Artery Bypass Graft Surgery: A Report of the American College of Cardiology/ American Heart Association Task Force on Practice Guidelines (Committee to Update the 1999 Guidelines for Coronary Artery Bypass Graft Surgery). Circulation, 110, e340. http://dx.doi.org/10.1161/01.CIR.63.2.285

[3] Caracciolo, E.A., Davis, K.B., Sopko, G., Kaiser, G.C., Corley, S.D., Schaff, H., et al. (1995) Comparison of Surgical and Medical Group Survival in Patients with Left Main Coronary Artery Disease Long-Term CASS Experience. Circulation, 91, 2325-2334. http://dx.doi.org/10.1161/01.CIR.91.9.2325

[4] Yusuf, S., Zucker, D., Passamani, E., Peduzzi, P., Takaro, T., Fisher, L., et al. (1994) Effect of Coronary Artery Bypass Graft Surgery on Survival: Overview of 10-Year Results from Randomised Trials by the Coronary Artery Bypass Graft Surgery Trialists Collaboration. The Lancet, 344, 563-570. http://dx.doi.org/10.1016/S0140-6736(94)91963-1

[5] Gowda, R.M., Fox, J.T. and Khan, I.A. (2008) Cardiogenic Shock: Basics and Clinical Considerations. International Journal of Cardiology, 123, 221-228. http://dx.doi.org/10.1016/j.ijcard.2006.03.099

[6] Quigley, R.L., Milano, C.A., Smith, L.R., White, W.D., Rankin, J.S. and Glower, D.D. (1993) Prognosis and Management of Anterolateral Myocardial Infarction in Patients with Severe Left Main Disease and Cardiogenic Shock. The Left Main Shock Syndrome. Circulation, 88, II65-II70.

[7] Antman, E.M., Anbe, D.T., Armstrong, P.W., Bates, E.R., Green, L.A., Hand, M., et al. (2004) ACC/AHA Guidelines for the Management of Patients with ST-Elevation Myocardial Infarction-Executive Summary: A Report of the American College of Cardiology/American Heart Association Task Force on Practice Guidelines (Writing Committee to Revise the 1999 Guidelines for the Management of Patients with Acute Myocardial Infarction). Journal of the American College of Cardiology, 44, 671-719. http://dx.doi.org/10.1016/j.jacc.2004.07.002

[8] Buszman, P.E., Kiesz, S.R., Bochenek, A., Peszek-Przybyla, E., Szkrobka, I., Debinski, M., et al. (2008) Acute and Late Outcomes of Unprotected Left Main Stenting in Comparison with Surgical Revascularization. Journal of the American College of Cardiology, 51, 538-545. http://dx.doi.org/10.1016/j.jacc.2007.09.054

[9] Ahn, J.-M., Roh, J.-H., Kim, Y.-H., Park, D.-W., Yun, S.-C., Lee, P.H., et al. (2015) Randomized Trial of Stents versus Bypass Surgery for Left Main Coronary Artery Disease: 5-Year Outcomes of the PRECOMBAT Study. Journal of the American College of Cardiology, 65, 2198-2206. http://dx.doi.org/10.1016/j.jacc.2015.03.033

[10] Serruys, P.W., Morice, M.-C., Kappetein, A.P., Colombo, A., Holmes, D.R., Mack, M.J., et al. (2009) Percutaneous Coronary Intervention versus Coronary-Artery Bypass Grafting for Severe Coronary Artery Disease. New England Journal of Medicine, 360, 961-972. http://dx.doi.org/10.1056/NEJMoa0804626

[11] Levine, G.N., Bates, E.R., Blankenship, J.C., Bailey, S.R., Bittl, J.A., Cercek, B., et al. (2011) 2011 ACCF/AHA/SCAI Guideline for Percutaneous Coronary Intervention: Executive Summary: A Report of the American College of Cardiology Foundation/American Heart Association Task Force on Practice Guidelines and the Society for Cardiovascular Angiography and Interventions. Journal of the American College of Cardiology, 58, 2550-2583. http://dx.doi.org/10.1016/j.jacc.2011.08.006

[12] Windecker, S., Kolh, P., Alfonso, F., Collet, J.-P., Cremer, J., Falk, V., et al. (2014) 2014 ESC/EACTS Guidelines on Myocardial Revascularization. European Heart Journal, ehu278.

[13] Sen, F., Ozeke, O., Kirbas, O., Burak, C., Kafes, H., Tak, B.T., et al. (2016) Classical Electrocardiographic Clues for Left Main Coronary Artery Disease. Indian Heart Journal, in press. http://dx.doi.org/10.1016/j.ihj.2016.03.025

"This case was performed at a different center. 